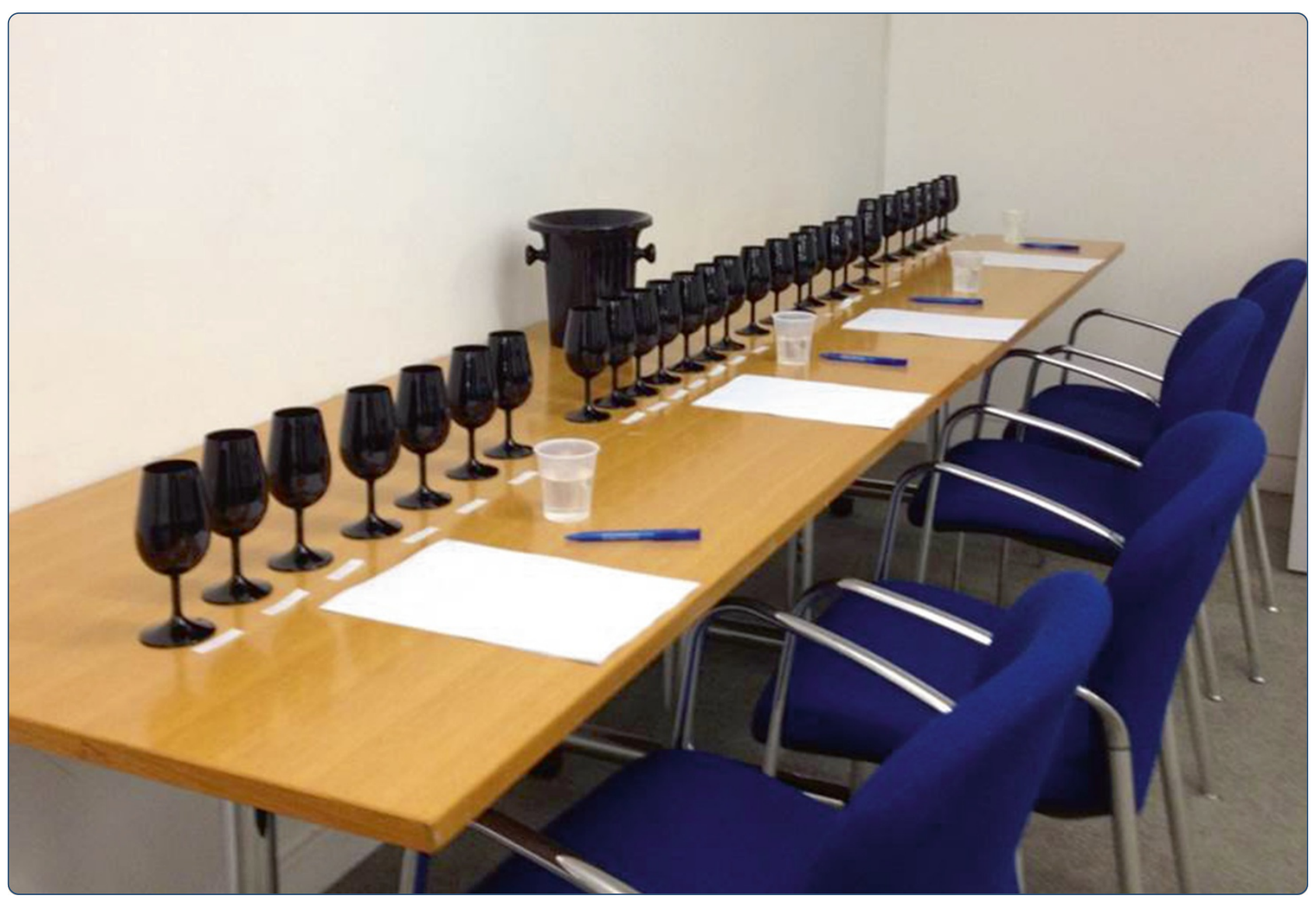

Grape expectations: how the proportion of white grape in Champagne affects the ratings of experts and social drinkers in a blind tasting

Harrar et al.

C Biomed Central 


\title{
Grape expectations: how the proportion of white grape in Champagne affects the ratings of experts and social drinkers in a blind tasting
}

\author{
Vanessa Harrar ${ }^{1 *}$, Barry Smith², Ophelia Deroy ${ }^{2}$ and Charles Spence ${ }^{1}$
}

\begin{abstract}
Background: Champagnes (or sparkling wines that are made using the 'méthode champenoise') are composed of white and/or red wine grapes. Their relative proportions are thought to contribute to a sparkling wine's distinctive flavour profile, but this has not yet been tested empirically. We, therefore, conducted a blind tasting experiment in which the participants had to report the perceived proportion of white grapes in a range of seven sparkling wines (including six Champagnes).

Results: The participants, including four expert, six intermediate, and five novice Champagne tasters, were unable to accurately judge the percentage of white grapes in the wines. Instead, the perceived proportion of white grape was correlated with the dosage and alcohol content of the wines. The hedonic ratings for the Champagnes did not correlate with price. Further, the more expensive Champagnes were only appreciated by the expert tasters.

Conclusions: Dosage and alcohol content appear to be the two attributes that tasters rely on when judging the contribution that different grape types make to the distinctive flavour of a sparkling wine. In the case of Champagne, flavour perception relies on a complex combination of factors including alcohol content, dosage, price expectancy, and experience with the product. The present results have implications for marketing Champagnes; they might be better if focused on the distinctive characteristics of each cuvee, or simplicity (blends versus nonblends), since these might be easier characteristics to detect than the proportion of white versus red grapes.
\end{abstract}

Keywords: Blind tasting, Blends, Sparkling wine, Grape colour, Champagne, Expertise

\section{Background}

Is the reputation that Champagne has amongst many consumers attributable to the quality of its component base wines and the craftsmanship of their blending, or is branding perhaps the major contributor to the perceived prestige of this drink? In his book Wine Scandal, Fritz Hallgarten ([1], pp. 116-117) describes an occasion in which a group of wine consultants tried to identify the glass containing the Champagne among ten sparkling wines. Virtually no one succeeded in this task. Interestingly, though, the consultants thought that whichever sparkling wine tasted best to them was the Champagne (often, this turned out to be a less expensive sparkling wine from somewhere such as Israel or

\footnotetext{
* Correspondence: vanessa.harrar@psy.ox.ac.uk

${ }^{1}$ Crossmodal Research Laboratory, Department of Experimental Psychology,

University of Oxford, South Parks Road, Oxford OX1 3UD, UK

Full list of author information is available at the end of the article
}

Luxembourg). Many studies have questioned the correlation between liking and price when wines are tested under blind tasting conditions (see [2], for a review). Casual reports have suggest that people follow a similar pattern with sparkling wines - that is, rating them on the basis of liking when tasted blind- but when brands are revealed, other attributes such as price, brand appreciation, Champenoise origin, or composition of grapes influence ratings considerably (for example, the higher the price, the better the perceived quality; [3-6]; see [7] for a review).

One of the few peer-reviewed studies to have looked specifically at Champagne was conducted by Lange and colleagues [8] on social drinkers in France. They presented participants with five brut non-vintage Champagnes varying in price from $€ 11$ to $€ 23$, three of which were bottles from a selection of well-known Champagne houses from the former 'Syndicat des Grandes Marques'.

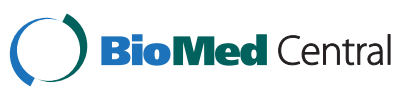


One group of participants had to rate how much they liked each Champagne, while another group had to say how much they would be willing to pay for it. Both groups performed these tasks under two conditions: first in a blind tasting condition, and then again when given the names of the producers. After the reveal, the participants were offered a chance to re-taste. Lange et al. reported differences for both ratings in the two conditions. On average, the social drinkers who were tested in this study were willing to pay significantly more for the top-brand Champagnes (which they reported liking more when the labels were revealed), and less for the unknown brands. In addition, knowing the identity of the brand (and, therefore, the approximate commercial price for the wine) introduced a greater degree of separation between the price estimates than it did for the hedonic scores. These results therefore suggest that, at least amongst social drinkers, the presence of effective labelling and branding (giving the taster information about typicity, prestige, cultural associations, price, etcetera) constitutes an influential factor in driving consumer preference. One important caveat to be kept in mind here though is that those participants who generally bought their Champagne from a producer were less influenced by the presentation of the bottle, while those participants who showed little or no brand loyalty attached greater importance to the label, showing, perhaps, relatively little knowledge of Champagnes. We hypothesized that expert tasters, who might be more attuned to the sensory properties of the product (intrinsic cues), would be less affected by extrinsic factors. Experts may be more likely able to detect the distinctive contribution that the different grapes make to its flavour without necessarily seeing the label (where such information is often available).

Champagnes are typically divided into three groups based on their grape composition: Blanc de Blancs (100\% Chardonnay, white grapes), Blanc de Noirs (100\% Pinot Noir and/or Pinot Meunier, red grapes), and blends (of white and red grapes). Blends report the exact proportion of each grape on the label as an indication of the flavour to expect. According both to the experts and to widespread belief, each grape variety brings a set of distinctive sensory features to the sparkling wine. Chardonnay is often described as bringing elegance and finesse, with Pinot Noir providing red-berry characteristics and structure, and Pinot Meunier providing both fruit aromas and roundness. According to the well-respected British wine critic Jancis Robinson, 'the Pinot Noir...provides the basic structure and depth of fruit in the blend...[Chardonnay] imparts a certain austerity and elegance to young champagnes, but is long-lived and matures to a fine fruitiness. [Pinot Meunier] provides many champagnes with an early- maturing richness and fruitiness'. The author goes on to note that Chardonnay 'has the greatest tendency to go toasty if aged after disgorgement, but can also develop finer, creamy, biscuity nuances' [9]. Pinot Noir 'does not retain its freshness for as many decades as Chardonnay but it arguably provides a more complex wine...goes biscuity rather than toasty, although toastiness is a common bottle aroma for this variety' [10]. Thus, the different grape compositions of Champagnes are said to result in different flavours, but how distinctive are the flavours? Tom Stevenson admits that 'a number of Blanc de Noirs can be so light that it is hard to imagine they do not contain some Chardonnay' [10]. With what degree of certainty, then, can experts work backwards from the flavour to determine the composition of a sparkling wine when tested blind?

The participants in this study ranged in expertise from novice to expert Champagne tasters. They were instructed to estimate the proportion of white grapes in seven sparkling wines (including six Champagnes) tasted blind. The participants were informed only that the sparkling wines could span the full range (from 0 to $100 \%$ Chardonnay grapes), and were chosen to provide a good range of values including $0,22,30,45,58$, and $100 \%$ Chardonnay grapes, with the remainder of the grapes made up of Pinot Noir and Pinot Meunier. Commonly available Champagnes were used in the study, thus making it impossible for us to vary the composition of red and white grapes while keeping other factors roughly constant. Dosage (sugar added to champagne after bottle fermentation) varied from 6 to $12 \mathrm{~g} / \mathrm{l}$, while amount of time on the lees varied from 1 to 8 years. These elements were factored into the data analysis in order to determine whether they correlated with the perceived proportion of white grapes, pleasantness, fruitiness, or sweetness ratings.

\section{Results}

Some questions were not answered by all participants (43 responses out of 15 subjects x 7 champagnes $\times 8$ dependent values, corresponding to approximately $5 \%$ of the data being missing). Missing data were not filled in since there were no repetitions, the wines varied considerably, and there were very few participants in each expertise group therefore there was no reasonable value that could be used as a substitute for the missing data. Degrees of freedom therefore fluctuate slightly between statistical tests. No data were removed or corrected; that is, no exclusion criteria were necessary. The results presented therefore represent all available data as is.

\section{Analysis of the sweetness and fruitiness ratings}

The sweetness and fruitiness ratings were analysed in order to determine whether there was a correlation 
between the two. There was no significant correlation between sweetness and fruitiness ratings when all of the data were tested together (across all participants, all wines, and all levels of expertise). Furthermore, none of the subsequent correlation analyses between sweetness and fruitiness, either at the level of individual participants, or at the level of specific groups of participants (experts, intermediate, novice), or looking at each wine separately, revealed any significant correlations either. Since sweetness ratings were not correlated with fruitiness ratings, these results argue against any kind of 'halo dumping' effect in the present data [11].

Halo dumping occurs when participants are provided with only one intensity scale (for example, sweetness) to rate a mixture of similar sensations (for example, sweetness and strawberry flavour). Forced to use one scale to describe both sensations, there is a danger that participants may 'dump' the second sensation onto the only available scale they have at their disposal. This effect disappears as soon as participants are provided with a scale for each sensation. The lack of a significant correlation between sweetness and fruitiness ratings speaks to the level of expertise, even of the novice group, in this experiment. A similar previous study (unpublished) with university students found significant correlations between the sweetness and fruitiness ratings for seven Champagnes (similar to those tested here) at all three self-reported levels of expertise. Here, however, while the novice and intermediate tasters did not report themselves as experienced Champagne tasters, the lack of any correlation between sweetness and fruitiness demonstrates their abilities in assessing wines, and gives credibility to their estimates of the proportion of white grape in the wines.

\section{Estimated proportion of white grapes}

Although certain participants accurately reported the proportion of white grape in some of the sparkling wines (see individual data plotted in Figure 1 - correct answers are points on the solid line), no one was correct more than two or three times. In order to determine whether the participants' responses were significantly different for the seven sparkling wines tasted, and in order to determine whether the pattern of responses differed reliably as a function of the three groups of responders (novice, intermediate, and expert), we compared the estimated proportion of white grapes for each of the sparkling wines with a mixed model analysis of variance (ANOVA). The within-participants factor was sparkling wine (seven levels) and the between-participants factor was experience (three levels). This analysis revealed no main effect of the type of sparkling wine $[\mathrm{F}(6,54)=$ $1.07, P=.39]$, no main effect of experience $[\mathrm{F}(2,9)=$ $1.28, P=.32]$, nor any interaction effect $[\mathrm{F}(12,54)<1$, n.s. $]$.
None of the groups (see also Figure 2) showed any consistent difference in their judgments concerning the proportion of white grapes in the various sparkling wines that were tasted. What about when the groups estimated the proportion of white grape for the champagnes at the two extreme ends of the scale (Blanc de Blanc and Blanc de Noir)?

The estimates for the sparkling wines containing 0 and $100 \%$ white grapes were compared in order to determine whether the participants reliably perceived the extreme difference in the proportion of white grapes. A t-test was performed in which we compared participants' responses to the Blanc de Noir (Mumm de Verzenay containing 0\% Chardonnay grapes) with the Blanc de Blanc (containing 100\% Chardonnay grapes). Once again, however, the results of this analysis revealed no significant difference $(\mathrm{t}(13)=.296, P=.386)$. Furthermore, the means were actually in the wrong direction; that is, more of the participants thought that the Blanc de Blanc contained a smaller proportion of Chardonnay grapes than the Blanc de Noir (see Figure 3). Looking at each of three groups separately, it can be seen that for both the intermediate and novice groups, the means are in the wrong direction $(\mathrm{t}(5)=.262, P=.402$; and $\mathrm{t}(3)=-1.15, P=.167$, respectively, see the black and grey symbols in Figure 3). That said, the responses from three out of four experts were in the right order (but not different enough to be significant, $(\mathrm{t}(3)=.792, P=.243$, see the blue symbols in Figure 3).

If the perceived proportion of white grape did not follow from the actual proportion, then what sensory qualities of the sparkling wines were the participants using in order to make this assessment? None of the methods which the participants reported they were using to determine the white grape content (aroma, flavour, and/or oral-somatosensory textural cues) produced any reliable correlations, or gave any advantage in terms of correctly determining the proportion of white grapes in the mix.

The perceived proportion of white grapes was, however, correlated with some other qualities of the Champagne: Dosage - the liquor and sugar added during fermentation - was negatively correlated $(\mathrm{N}=99$, Spearman's rho $=-.255, P=.011)$, while the alcohol content was positively correlated $(\mathrm{N}=99$, Spearman's rho $=.231, P=.021$, see Figure 4$)$. Participants' estimates concerning the proportion of white grapes increased as the dosage decreased, and as the alcohol content increased. Note that true alcohol and dosage levels in the champagne were negatively correlated $(\mathrm{N}=7, \mathrm{r}=-.813, P=.026)$.

\section{The certainty of participants' responses}

Participants also had to rate the certainty with which they reported the perceived proportion of white wine (where 1 


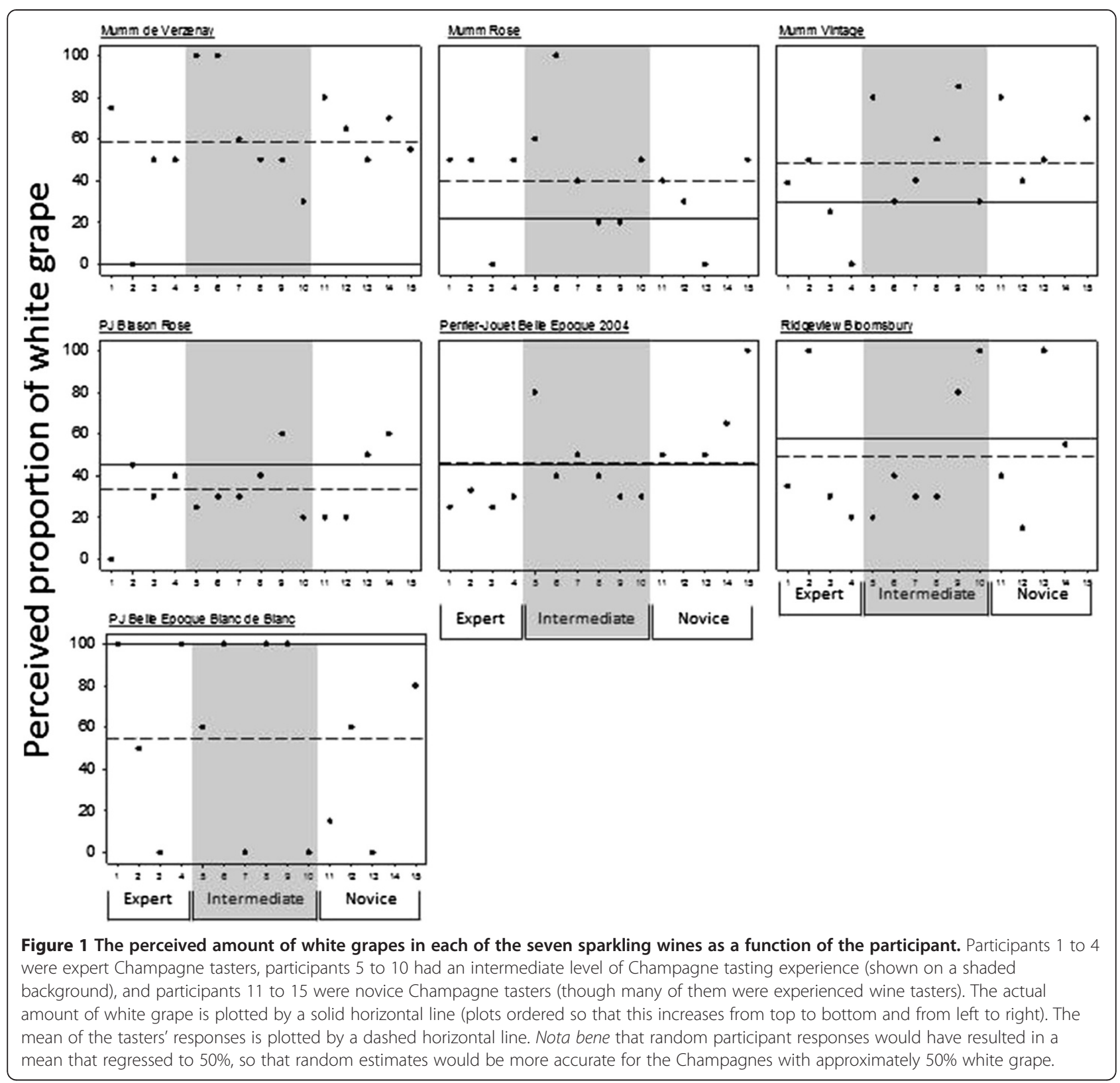

corresponded to 'not at all certain' and 10 corresponded to 'extremely certain'). The data concerning the certainty of participants' responses were analysed using the same mixed model ANOVA as described previously (Wine - 7 levels; Expertise - 3 levels). While expert tasters were more certain (mean certainty $5.18 \pm$ standard error 1.19) than the intermediate $(4.97 \pm 1.07)$, or the novice tasters $(3.71 \pm 1.38)$, there was no main effect of expertise $\left(F_{2,9}=\right.$ $1.051, P=.389)$. Further, while participants were most certain with reports concerning the Mumm Rosé (5.81 \pm 0.79 ), and least certain of their judgments for the Mumm Vintage 2004 (4.02 \pm 0.63$)$ there was no significant main effect of sparkling wine. There was no interaction between the factors (both $\mathrm{F}<1$ ).

\section{Hedonic ratings}

What made the participants like or dislike a particular sparkling wine? We tested correlations of hedonic ratings with the perceived proportion of white grape, perceived sweetness, fruitiness, familiarity, or vintage/ $\mathrm{NV}$; and known attributes of each wine (actual proportion of white grape, dosage, alcohol content, amount of time on the lees, or price). The overall score given to the sparkling wine (out of 10, where 10/10 is excellent) was correlated with fruitiness $(\mathrm{N}=102$, Spearman's rho $=.355, P<.001)$, vintage $/ \mathrm{NV}$ assumptions $(\mathrm{N}=98$, Spearman's rho $=-.373$, $P<.001$; negative correlation indicates that higher ratings were associated with 'vintage'), and familiarity scores $(\mathrm{N}=95$, Spearman's rho $=.589, P<.001)$ (Figure 5). 


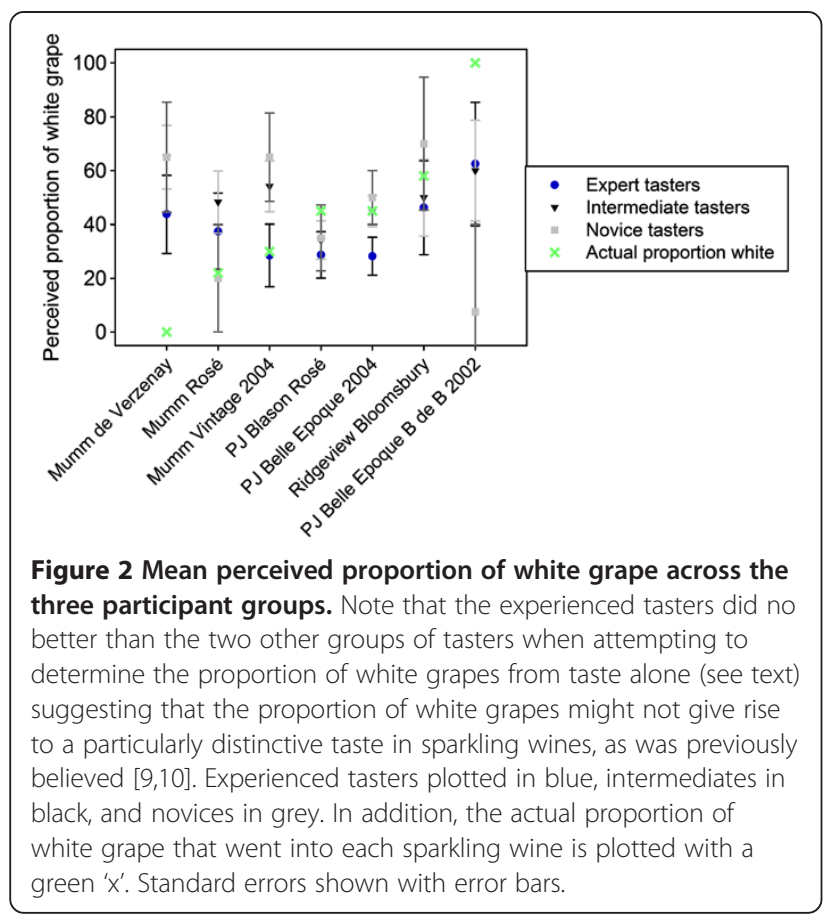

Most importantly, hedonic ratings did not correlate with the objective price of the bottles (Spearman's rho $=.032, P=.748$, see Figure 5 ). In fact, the price of the sparkling wines was not correlated with any of the participants' ratings or perceptions (obtained from the

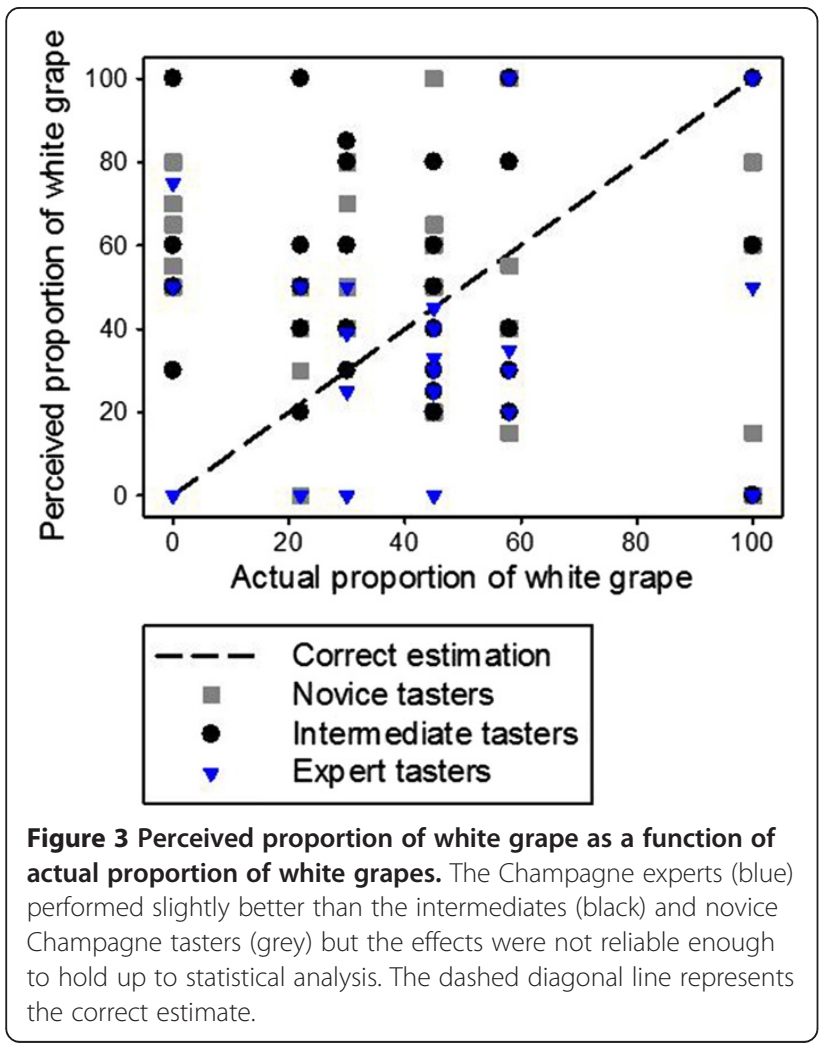

responses in the questionnaire); it was only correlated with the number of years that the wine had been left on its lees before being bottled $(\mathrm{N}=7$, Spearman's rho $=.865, P<.012)$, which is a vintage characteristic. If not the most expensive, which wines were most well liked, if any?

Figure 5 shows group ratings that have been normalised based on each participant's mean rating, so that positive values indicate that the participants in that group rated the wine above their individual average. Perrier-Jouet Belle Epoque Blanc de Blanc 2002 had the lowest overall rating (rating of 5.86/10, retail price $£ 400$ ) Mumm Vintage 2004 and Perrier-Jouet Belle Epoque 2004 were rated highest (rating of $7.13 / 10$, retail price $£ 40$ and $£ 100$, respectively). Although there were small variations in ratings, there were no significant differences between the ratings across the sparkling wines. Similar results were obtained in an unpublished primary and smaller scale study conducted with Oxford University students. There was also no significant interaction between the ratings on the seven sparkling wines and level of expertise.

It might be that the Perrier-Jouët Belle Epoque Blanc de Blanc 2002 ( $£ 400)$ was simply not showing very well; the wine professional who tasted the samples suggested that it appeared less expressive than normal on the palate and had a slight cheese or sweaty note on the nose (reminiscent of isovaleric acid, a characteristic of Brettanomyces spoilage). Alternatively, it might be the case that specialty or aged cuvées can only really be appreciated by expert champagne tasters with significant experience (that is, they may be an acquired taste). Innately unpalatable foods can often become pleasant (for example, chili and coffee) but this requires, among other things, repeated exposure (see discussion of hedonic reversals in [12], p.402).

\section{Colour from aroma ratings}

Perrier-Jouët Blason Rose was rated as having the most reddish aroma (rating of $2.44 ; 55 \%$ red grape) while Mumm de Verzenay had the greenest aroma (rating of $5.11 ; 100 \%$ red grape). Analysing the aroma-colour association (1-red, 7-green, see Figure 6), with the same mixed model ANOVA as described previously revealed no significant difference across the seven sparkling wines, no difference across expertise groups, and no interaction between the two ( $\mathrm{F}<1$ for each, N.S.).

\section{Discussion}

The results of the present study, conducted with a range of sparkling wines, suggests that people, no matter whether they are expert Champagne tasters, expert wine tasters, or simply social drinkers, are unable to reliably determine the proportion of white Chardonnay grapes in 

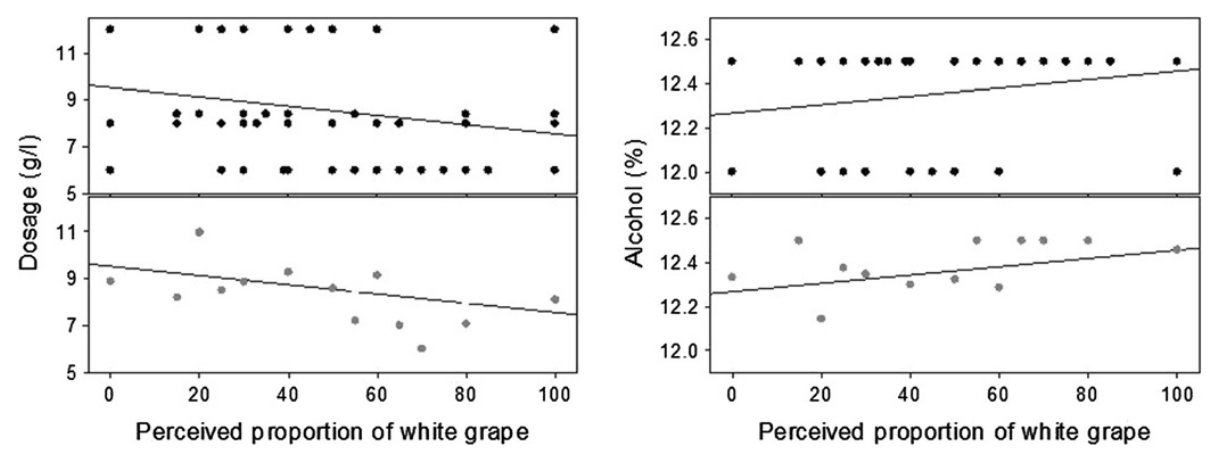

Figure 4 The alcohol content and the dosage (sugar added during fermentation) plotted as a function of the perceived proportion of white grape and fitted with a linear regression. Actual data points are plotted in upper panel with filled black circles (nota bene that many of the points lie directly on top of each other). To enable easier viewing of the correlation effect, the bottom panel plots the means $y$-value for each $x$-value that is repeated (filled grey circles are means)

the sparkling wines when tasted blind. We found that dosage and alcohol content are attributes that tasters actually rely on when judging the contribution each grape type makes to the distinctive flavour of a sparkling wine.

Our findings are in line with those studies of still wine that have investigated the ability of people (experts and non-experts) to sort wines in terms of the characteristics coming from the grape (that is, the 'primary aromas') rather than properties of the wine added by vinification, bottle fermentation, lees contact (amount of time the bottle-fermented wine is left in contact with the dying

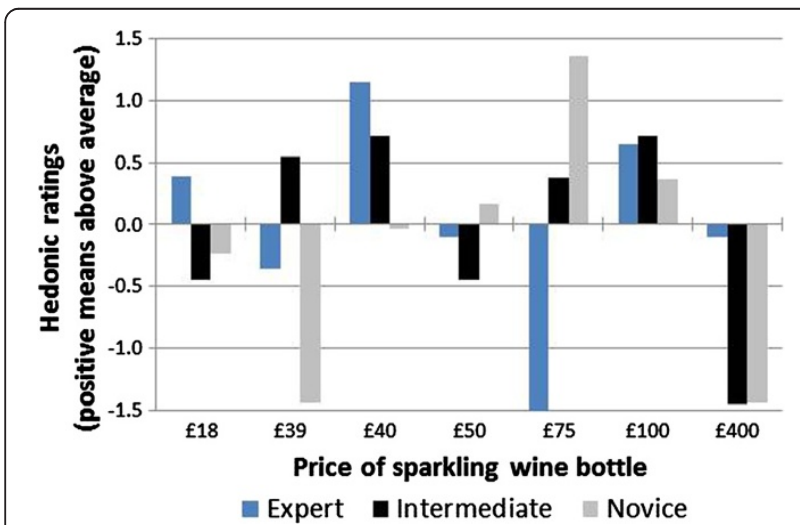

Figure $\mathbf{5}$ Variation in hedonic ratings as a function of group and the price of the sparkling wine. Hedonic ratings were initially reported on a scale of 1 to 10 . Each participant's ratings were normalised based on the individual's mean. The group means and standard errors are plotted here (experts in blue, intermediates in black, and novice tasters in grey) for each bottle of sparkling wine. The experts and intermediates gave the highest ratings for the $£ 40$ Mumm Vintage 2004, while the novices preferred the $£ 75$ Blanc de Noir, Mumm de Verzenay. The experts rated the Perrier-Jouët Belle Epoque Blanc de Blancs 2002 ( $£ 400)$ as average, which was much better than either the intermediate or novice drinkers who rated it well below average, suggesting that particularly expensive (aged) wines might only be appreciated by experienced tasters. yeasts before disgorgement when the yeast deposits are removed and the wine is re-corked), and elevage (the process of maturing the base [still] wine in oak barrels), or extrinsic cues from branding and labelling [13-15]. These results add to the literature on the blind tasting of sparkling wines $[1,8]$ suggesting that this extrinsic information might contribute to what people report as being the characteristic tastes (or qualities) of certain varieties of sparkling wine.

However, the sparkling wines in this study did not vary along a single dimension. In addition to variations in the proportion of white grapes, they were also different in terms of the place the wine came from, as well as its vintage, quality, alcohol content, and dosage. These various factors introduce further complexity to the tasters' task, but at the same time make the testing/tasting situation more realistic. Still, future experiments could test an expert's ability to make finer grain comparisons of wines (for example, from the same vintage, or different cuvées or vintages from the same Champagne house, or sort white grape-only wines from different regions - see [15]). A skilful chef de cave might be able to discover, after experimenting with particular blends, the difference each component makes to the overall well-integrated flavour of the Champagne.

Although the results show that experienced Champagne drinkers are not able to judge the contribution of each grape variety to the flavour of a Champagne, tasters certainly recognised differences between the wines and rated them differently. It would therefore be wrong to infer from the fact that tasters cannot perceive the difference that the proportion of the various grape varieties makes to the blend, that it did not make a difference to the resulting flavour of the blend. Instead, we hypothesise that success in blending has made it more difficult for tasters to identify the particular contributions made by each grape variety to the overall flavour profile. This 


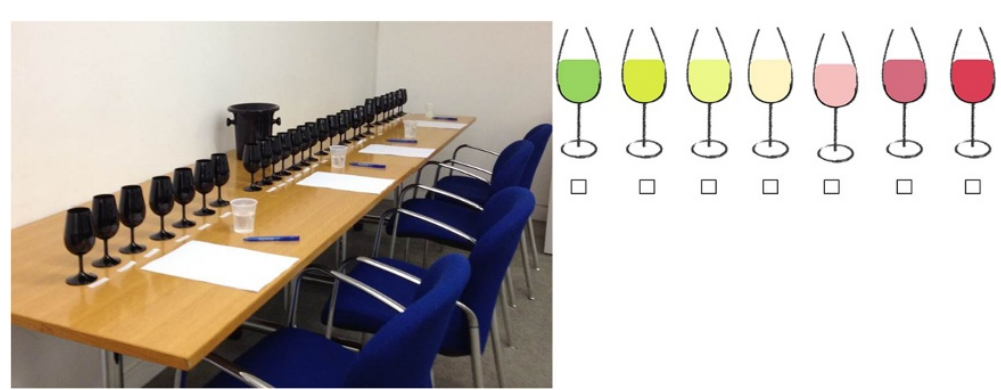

Figure 6 Experimental set-up. On the left, the table is laid out with glasses and the questionnaires are shown. On the right, the first question in the response booklet is demonstrated. For this question, participants had to choose which of the seven coloured cups best matched the smell/ nose of the sparkling wine. For half of the participants, the left-right ordering of the colours was reversed (that is, the deep red glass appeared on the left of the score sheet).

suggests another intriguing possibility worthy of further investigation: Whether complexity might be more easily recognised than the actual components in the wine. In support of this point, we found that Perriet Jouet Belle Epoque Blanc de Blanc was correctly identified as a non-blend by nine tasters (five were correct, while another four people guessed it was a Blanc de Noir; see Figure 1). Other samples were speculated to be nonblends by at most three tasters. It would be interesting for future studies to compare the perceptual heuristics applied to simplicity versus complexity in blended and non-blended wines.

Another interesting result to emerge from the present study is the fact that there was no correlation between the objective price of the bottles and our participants' preference ratings for the sparkling wines tasted blind. This replicates previous results [8], and extends them over a much wider price range $(€ 11$ to $€ 23$ in Lange et al.; $£ 18$ to $£ 400$ here). A lack of correlation between preference and price fits with the much larger body of research on still wines (see [2] for a review). We would also like to suggest, as an area for future research, that this effect might be different for experienced tasters as compared to social drinkers. Based on these results, we suggest that more expensive champagnes, with attributes related to ageing, might only be appreciated by expert tasters who are more likely to have previously experienced such flavour profiles.

Were the self-declared expert Champagne tasters in the present study a representative sample? Of course, with more expert tasters some tests would have been more powered and certain of the null results might have reached significance (for example, with about 15 experts reporting in the same way as the four that were tested here, there would be enough power to reliably conclude that experts estimate the Blanc de Blanc as having more Chardonnay than the Blanc de Noir). However, such a large sample of expert Champagne drinkers might not be possible outside the region. Instead, as described in the Methods section, all the participants tested in this study had professional activities related to wine or spirits, including the novice and intermediate Champagne tasters. Some of those that self-assessed themselves as expert Champagne tasters were writers and journalists on the topic (note that previous verbalization of characteristics of wines tasted may have affected their taste perception $[16,17]$ ), while others indicated that they were wine merchants. The individuals we tested are likely to have had significantly more experiences and exposure to Champagne than those tested in previous research $[1,8]$, making these results highly novel. The high baseline of tasting knowledge across the whole sample is demonstrated by the lack of correlations between the sweetness and fruitiness ratings for the wines. Using a lack of correlation between perceptually 'similar' attributes might provide an independent means of categorizing people as expert or non-expert tasters in future research.

Were the champagnes fairly presented? Participants in the present study only had limited access to cues such as the size of the bubbles, the quality of the mousse, and the amount of dissolved $\mathrm{CO}^{2}$ since they were sampling in random order sequentially. For example, the size of the bubbles can be used to distinguish between Champagne and Cava. These cues provide quality information which could have been used by the tasters to distinguish between the wines they were sampling [18-20], but there is little evidence to suggest that they would provide information about the proportion of white versus red grapes in the wine. Colour, on the other hand, could have provided an important cue. This study therefore employed blind tasting.

Although blind tasting is a technique that is commonly used, it may not provide results that are transferrable to normal, namely sighted, taste perception. Pangborn and her colleagues [21] revealed that experts 
rated a rosé-coloured white wine as being sweeter than the untainted (uncoloured) white wine. By contrast, the non-experts' sweetness ratings were not influenced by the colour of the wine. As such, experts who, knowingly or unknowingly, use colour when assessing the proportion of white and red grapes in a sparkling wine might be misled [22-24]. It is also worth noting that the glass itself may also have had an influence on the flavour [25].

\section{Conclusions}

The current study balanced laboratory testing procedures (using professional black tasting glasses) with a set of realistic wines that varied in composition along multiple dimensions. The group of expert Champagne tasters was not able to reliably determine the proportion of white grapes in the seven sparkling wines tasted. One should certainly not conclude from our results that the percentage of these grapes makes no difference to the taster's experience (most of the participants distinguished between the Champagnes, as seen from the variability in their responses to each wine). Instead, it seems that the contribution to flavour that the proportion of these grapes makes cannot be detected. Indeed, the goal in blending wines is that their component parts - fruit, acidity, alcohol, lees character - are all present but with no single attribute dominating the others. That is, a 'well blended' or balanced wine may well disguise the components that have gone into producing the resulting flavour. Further experiments are therefore needed in order to assess the tentative interpretation of the results put forward here, results which could contribute significantly to the as yet ill-understood notion of simplicity and complexity in flavour perception.

\section{Methods}

\section{Participants}

Fifteen participants gave their informed consent prior to taking part in the tasting. Their median age was 30 years (ranging from 21 to over 60) and 11 were male. The studies have been approved by the Central University Research Ethics Committee of the University of Oxford and are therefore in compliance with the Helsinki Declaration. The whole sample had been involved in professional activities related to wine or spirits. To assess Champagne expertise, in particular, the participants were given the following questions: 'How would you rate your experience with Champagne? Novice, intermediate, or expert' and 'Is your professional activity related to Champagne? Yes, no, please specify'. We chose to avoid mixing kinds of expertise because perceptions of wine are known to differ among different kinds of experts [26]. For instance, experts included critics but importantly did not include any wine-makers or sommeliers. As such, there were four expert Champagne tasters who included wine merchants, well-known
Champagne critics/journalists/writers specializing in champagne, and trade ambassadors for a Champagne house. There were six intermediate Champagne tasters, which included wine and spirit trade retailers, writers/journalists for food and wine columns, and sales representatives for Champagne houses. Finally, there were five self-assessed novice Champagne tasters, who included wine brand owners, people who worked for a Champagne house, wine trade, and spirit ambassadors who generally drank Champagne monthly.

\section{Stimuli}

The seven sparkling wines used in the present study consisted of six Champagnes: Mumm de Verzenay, Mumm Rosé, Mumm Vintage 2004, Perrier-Jouët Blason Rosé, Perrier-Jouët Belle Epoque 2004, Perrier-Jouët Belle Epoque Blanc de Blancs 2002, and a Ridgeview Bloomsbury Non-Vintage Sparkling wine from Sussex (UK) - the only sparkling wine not made in Champagne but made of the same grape varieties and using the same method. These wines were chosen to provide a range from 0 to $100 \%$ Chardonnay grapes (see Table 1; [see Additional file 1 for the tasting notes for each wine]).

To ensure quality control, each bottle of sparkling wine was tasted by a professional (not included as a participant in the study) before being poured. This step ensured that none of the bottles had any obvious faults. At the end of the experiment, all of the sparkling wines were re-tasted by the same professional (once they had warmed-up significantly). The expert suggested that one of the bottles of Perrier-Jouët Belle Epoque Blanc de Blancs 2002 might not have been showing all that well. It had some slight characteristics of Brettanomyces spoilage (cheese or sweaty note on the nose) and was somewhat less expressive than usual, but it was by no means definitely off.

The wines were presented to the participants in professional black ISO tasting glasses that had just been put through the dishwasher; the expert who was asked to check the glasses, and was sensitive to potential problems with residual detergent, detected no such problem. The wines were served at the same temperature (they were removed from refrigeration at the same time) and had nearly the same amount of time to breath before being tasted (the first glass was poured about five minutes before the last glass, and approximately 15 minutes before the participants began tasting).

\section{Design}

The experiment was conducted in the University of London in a quiet, well-lit air-conditioned room. Participants sat at a table with at least $1 \mathrm{~m}$ spacing between adjacent tasters. A line of seven opaque black glasses containing a tasting quantity of the sparkling wines (each 
Table 1 The seven sparkling wines (including six Champagnes) evaluated in the present study

\begin{tabular}{|c|c|c|c|c|c|c|c|c|}
\hline \multirow{2}{*}{$\begin{array}{l}\text { Sparkling wine } \\
\text { Name }\end{array}$} & \multirow[t]{2}{*}{ Year } & \multirow{2}{*}{$\begin{array}{c}\text { \% White grapes } \\
\text { Chardonnay }\end{array}$} & \multicolumn{2}{|c|}{$\%$ Red grapes } & \multirow{2}{*}{$\begin{array}{c}\text { Alcohol } \\
\text { (\%) }\end{array}$} & \multirow{2}{*}{$\begin{array}{c}\text { Dosage } \\
(g / l)\end{array}$} & \multirow{2}{*}{$\begin{array}{l}\text { Lees } \\
\text { (years) }\end{array}$} & \multirow{2}{*}{$\begin{array}{c}\text { Retail } \\
\text { price }(£)\end{array}$} \\
\hline & & & Pinot Noir & Pinot Meunier & & & & \\
\hline Mumm de Verzenay & NV & - & 100 & - & 12.5 & 6 & 5 & 75 \\
\hline Mumm Rosé & NV & 22 & 60 & 18 & 12.0 & 12 & 3 & 39 \\
\hline Mumm Vintage & 2004 & 30 & 70 & - & 12.5 & 6 & 5 & 40 \\
\hline Perrier-Jouët Blason Rosé & NV & 45 & 50 & 5 & 12.0 & 12 & 1.08 & 50 \\
\hline Perrier-Jouët Belle Epoque & 2004 & 45 & 50 & 5 & 12.5 & 8 & 6 & 100 \\
\hline Ridgeview Bloomsbury & 2009 & 58 & 30 & 12 & 12.5 & 8.4 & 0.67 & 18 \\
\hline Perrier-Jouët Belle Epoque & 2002 & 100 & - & - & 12.5 & 8 & 8 & 400 \\
\hline Blanc de Blancs & & & & & & & & \\
\hline
\end{tabular}

NV, non-vintage.

labelled with a random three-digit code), a questionnaire booklet, and a pen were placed in front of each participant's place prior to their arrival at the testing station (see Figure 6). The wines were randomly ordered between participants and three-digit codes were used to identify which set of answers corresponded to which wine. An opaque black spittoon was placed at each table. Each participant was also given a glass of water for rinsing as necessary.

The group of participants received a three-minute briefing at the start of the session to ensure that they all had the same background information and instructions prior to the experiment. The participants were informed that the sparkling wines could cover the full range of proportions of Chardonnay grapes (the questionnaire also said 0 to $100 \%)$. They were told that certain glasses might contain the same wine. They were informed that their neighbours might have different wines, and that they would likely be presented in a different order. They were instructed to begin tasting (and rating) with the glass on the far left and progress rightward, turning to a new page for each new wine. They were told not to go back to any of their previous glasses (or answer sheets) once they had moved on.

For each wine sample, there were a total of nine questions asked exactly as presented below (that is, there were no visual analogue scales) except that Question 1 was preceded by the image of coloured glasses displayed in Figure 6. The participants were informed that they should answer the first question before tasting (as it related to the smell/nose of the wine). Each question from the questionnaire was briefly explained and participants had the opportunity to ask for further clarification. During this process, the experimenter clarified that the overall rating (Q6) referred to hedonic preference (not the quality of wine per se), and Q9 was where tasters could hazard a guess at the brand/producer/type of champagne. There was also a blank space where tasters were invited to write down any tasting notes they might have.
Since $50 \%$ of Q9 was left blank, it was not analysed; for reference, of the 55 guesses (from 15 participants and seven Champagnes), seven were correct. The majority of the participants took no more than 40 minutes to complete the tasting.

1. Which colour best matches the smell of the Champagne? (see Figure 6)

2. What percentage of the Champagne is made from White grapes? (0 to 100)

3. How certain are you of the proportion of white grapes in the Champagne? (1-Not at all certain; 10-Extremely certain)

4. How SWEET is the Champagne? (1-Not at all sweet; 10-Extremely sweet)

5. How FRUITY is the Champagne? (1-Not at all fruity; 10-Extremely fruity)

6. Rate the Champagne (out of 10) (where a higher value indicated a higher rating)

7. Do you think the Champagne is Vintage? (Non-Vintage or, if Vintage, give a year)

8. Are you familiar with this Champagne? (1-Not at all familiar; 10-Extremely familiar)

9. What would you say this Champagne is?

\section{Additional file}

Additional file 1: The tasting notes for all sparking wines tested.

\section{Abbreviations}

ns: Not significant; nv: Non-vintage.

\section{Competing interests}

The authors declare that they have no competing interests.

\section{Authors' contributions}

$\mathrm{VH}$ performed the statistical analysis and drafted and revised the manuscript. $\mathrm{VH}, \mathrm{BS}, \mathrm{OD}$, and CS designed the study, prepared the stimuli, collected the data, and revised the manuscript. All authors read and approved the final manuscript. 


\section{Authors' information}

$\mathrm{VH}$ has a PhD in psychology from York University (Toronto, Canada) and works as a post-doc in CS's lab in the Department of Experimental Psychology at Oxford University (Oxford, UK). BS has a PhD in Cognitive Science from the University of Edinburgh and is founding director of the Centre for the Study of the Senses at the Institute of Philosophy, University of London. OD has a PhD from the Universite de Paris XII and is a Marie Curie Fellow at the Centre for the Study of the Senses at the Institute of Philosophy, University of London. CS has a PhD in Experimental Psychology from the University of Cambridge and has been a University Lecturer at Oxford University since 1997

\section{Acknowledgements}

Vanessa Harrar holds a Mary Somerville Junior Research Fellowship from Somerville College, Oxford University, UK. Ophelia Deroy is funded by a Marie Curie IEF. Barry C Smith is funded by the AHRC for a project on Flavour Perception. We would also like to thank Matt Day for his help at the tasting event and Pernod-Ricard, who hosted the Champagne Assembly Day. Finally, we would like to thank Mumm Champagne and Perrier-Jouët for donating the Champagne.

\section{Author details}

${ }^{1}$ Crossmodal Research Laboratory, Department of Experimental Psychology, University of Oxford, South Parks Road, Oxford OX1 3UD, UK. ${ }^{2}$ Centre for the Study of the Senses, University of London, Senate House, Malet Street, London WC1E 7HU, UK.

Received: 5 June 2013 Accepted: 2 September 2013

Published: 29 November 2013

\section{References}

1. Hallgarten F: Wine Scandal. London: Sphere Books Ltd; 1987

2. Spence $\mathrm{C}$ : The price of everything - the value of nothing? World of Fine Wine 2010, 30:114-120

3. Angulo AM, Gil JM, Gracia A, Sanchez M: Hedonic prices for Spanish red quality wine. Br Food J 2000, 2:481-493.

4. Combris $P$, Lecocq $S$, Visser M: Estimation of a hedonic price equation for Bordeaux wine: Does quality matter? Econ J 1997, 107:390-402.

5. Oczkowski E: A hedonic price function for Australian premium table wine. Aust J Agric Econ 1994, 38:93-110.

6. Wade C: Reputation and its effect on the price of Australian wine. Austr New Zealand Wine Ind J 1999, 14:82-84.

7. Mueller S, Osidacz P, Francis L, Lockshin L: Combining discrete choice and informed sensory testing in a two-stage process: Can it predict wine market share? Food Qua Prefer 2010, 21:741-754.

8. Lange C, Martin C, Chabanet C, Combris P, Issanchou S: Impact of information provided to consumers on their willingness to pay for Champagne: Comparison with hedonic scores. Food Qual Prefer 2002, 13:597-608.

9. Robinson J: The Oxford Companion to Wine. 3rd edition. Oxford: Oxford University Press; 2006

10. Stevenson T: Christie's World Encyclopaedia of Champagne Sparkling Wine. Bath: Absolute Press; 2003.

11. Clark CC, Lawless HT: Limiting response alternatives in time-intensity scaling: An examination of the halo dumping effect. Chem Senses 1994, 19:583-594.

12. Rozin P: Food and eating. In Handbook of Cultural Psychology Edited by Kitayama SE and Cohen DE. New York: Guilford Press; 2007:391-416.

13. Ballester J, Patris B, Symoneaux R, Valentin D: Conceptual vs. perceptual wine spaces: Does expertise matter? Food Qua Prefer 2008, 19:267-276.

14. Parr W, Green J, White K, Sherlock R: The distinctive flavour of New Zealand Sauvignon Blanc: Sensory characterisations by wine professionals. Food Qual Prefer 2007, 18:849-861.

15. Parr W, Valentin D, Green J, Dacremont C: Evaluation of French and New Zealand Sauvignon wines by experienced French wine assessors. Food Qual Prefer 2010, 21:56-64.

16. Hughson AL: Wine expertise: Current theories and findings regarding its nature and bases. Food Aus 2003, 55:193-196.

17. Melcher JM, Schooler JW: The misremembrance of wines past: Verbal and perceptual expertise differentially mediate verbal overshadowing of taste memory. J Mem Lang 1996, 35:231-245.
18. Liger-Belair $G$, Beaumont $F$, Jeandet P, Polidori $G$ : Flow patterns of bubble nucleation sites (called fliers) freely floating in champagne glasses. Langmuir 2007, 23:10976-10983.

19. Liger-Belair $G$, Beaumont $F$, Vialatte M-A, Jégou S, Jeandet $P$, Polidori $G$ : Kinematics and stability of the mixing flow patterns found in champagne glasses as determined by laser tomography techniques: Likely impact on champagne tasting. Anal Chim Acta 2008, 621:30-37.

20. Liger-Belair $\mathrm{G}$, Bourget $\mathrm{M}$, Pron $\mathrm{H}$, Polidori G, Cilindre $\mathrm{C}$ : Monitoring gaseous $\mathrm{CO}_{2}$ and ethanol above champagne glasses: Flute versus coupe, and the role of temperature. PLOS ONE 2012, 7:e30628.

21. Pangborn RM, Berg HW, Hansen B: The influence of color on discrimination of sweetness in dry table-wine. Am J Psychol 1963, 76:492-495.

22. Morrot G, Brochet F, Dubourdieu D: The color of odors. Brain Inj 2001, 79:309-320

23. Spence C: The colour of wine - Part 1. World of Fine Wine 2010, 28:122-129.

24. Spence C: The colour of wine - Part 2. World of Fine Wine 2010, 29:112-119.

25. Spence $C$, Harrar $V$, Piqueras-Fiszman B: Assessing the impact of the tableware and other contextual variables on multisensory flavour perception. Flavour 2012, 1:7.

26. Smith BC: The objectivity of Tastes and Tasting. In Questions of Taste: The Philosophy of Wine. USA: Oxford University Press; 2007:41-78.

doi:10.1186/2044-7248-2-25

Cite this article as: Harrar et al:: Grape expectations: how the proportion of white grape in Champagne affects the ratings of experts and social drinkers in a blind tasting. Flavour 2013 2:25.

\section{Submit your next manuscript to BioMed Central and take full advantage of:}

- Convenient online submission

- Thorough peer review

- No space constraints or color figure charges

- Immediate publication on acceptance

- Inclusion in PubMed, CAS, Scopus and Google Scholar

- Research which is freely available for redistribution 